\title{
Novel cycloaurated gold(III) complexes and their effects on styrene polymerization
}

\author{
Murat Emre Hanhan
}

Published online: 8 February 2011

(C) The Author(s) 2011. This article is published with open access at Springerlink.com

\begin{abstract}
Novel cycloaurated gold(III) complexes were prepared by using Schiff bases with different substituents. Effects of the synthesized gold(III) complexes and substituent groups on styrene polymerization were investigated. As a result of these investigations, it was observed that gold(III) complexes could not catalyze polymerization reaction without addition of a co-catalyst like $\mathrm{NaBAr}_{4}{ }_{4}\left(\mathrm{Ar}^{\prime}=3,5\right.$-bis(trifluoromethyl)phenyl). All ligands and complexes were characterized by using ${ }^{1} \mathrm{H}$ nuclear magnetic resonance (NMR), ${ }^{13} \mathrm{C}$ NMR, LC-MS, elemental analysis and FT-IR techniques. The architecture of the polymer was determined as an atactic or sydiotactic polymer by using ${ }^{13} \mathrm{C}-\mathrm{NMR}$ and $\mathrm{DSC}$ techniques. Molecular weights of the polymers were analyzed by using gel permeation chromatogram (GPC).
\end{abstract}

Keywords Gold(III) - Cycloauration .

Styrene polymerization

\section{Introduction}

Cyclometallation reaction of gold(III) is one of the most important reactions of direct C-H bond activation. In 1989, Constable and Leese discovered first cycloauration by using 2-phenylpyridine [1]. Applications of organogold chemistry have been explored by Hashmi [2-4]. Organic derivatives of both $\mathrm{Au}(\mathrm{I})$ and (III) ions were reported in the review and in more recent papers [5-13].

M. Emre Hanhan $(\bowtie)$

Department of Chemistry, Zonguldak Karaelmas University,

Zonguldak 67100, Turkey

e-mail: emrehanhan@karaelmas.edu.tr

M. Emre Hanhan

e-mail: emrehanhan@hotmail.com
Polystyrene is a hard plastic and more common in our everyday life. The stereoregular state of the polymer is important because it determines the crystallinity and physical properties of the resulting polymer. In general, transition metals are used for styrene polymerization in radicalic polymerization reaction and polystyrene obtained are generally isotactic reach atactic form [14]. But syndiotactic polystyrene (s-PD) is more useful than atactic polystyrene (a-PS) with a high melting point of $\sim 270^{\circ} \mathrm{C}$, a glass transition temperature similar to atactic polystyrene, a fast crystallization rate, a high modulus of elasticity and an excellent resistant to heat and chemical agents [15]. Because of these properties, an immediate commercialization of syndiotactic polystyrene was successfully performed by the Idemitsu Kosan Company in a semicommerical plant of approximately 5,000 t/year in Chiba/ Japan and by The Dow Chemical Company, based on a pilot plant in Midland, Michigan. The first commercial sPS plant worldwide at a capacity of about 36,000 t/year in Schkopau, Germany opened in 1999, and continued by Idemitsu Kosan in a modernized production facility in Chiba, Japan, in 2006 [16]. In automotive systems, s-PS can be applied in power distribution centers under the hood, in electrical lighting, and electronics, s-PS can be used successfully for connectors, plugs and sockets, glass-fiber-reinforced and color-stabilized s-PS grades are materials for iron skirts and at least very promising markets of s-PS are food and water contact applications [17]. Especially half-metallocene transition metal complexes are very effective catalysts to synthesize s-PS $[18,19]$. Although, gold complexes used for a wide array of transformations, there are few reports on the usage of gold complexes for polymerization reactions. In 2008, Perez and co-workers highlighted that polymerization mechanism of styrene with gold-carbene complexes is not working without using a co-catalyst like $\mathrm{NaBAr}_{4}{ }_{4}$. Their 
reaction results showed that their polymerization mechanism was cationic type [20]. But they did not explain the role of gold center.

In this work, we synthesized three cycloaurated gold(III) complexes to investigate their catalytic activity and reaction mechanism on styrene polymerization with using $\mathrm{NaBAr}_{4}$ as a co-catalyst. As a result, when styrene is alone with $\mathrm{NaBAr}_{4}^{\prime}$, reaction resulted with isotactic to reach atactic polystyrene, but when gold(III) complexes are added to the reaction, the polymer we gained was syndiotactic which is more valuable than atactic form.

\section{Synthesis and characterization}

All of the synthesized ligands and complexes (Fig. 1) were characterized with a combination of elemental analysis, LCMS, ${ }^{1} \mathrm{H}$ and ${ }^{13} \mathrm{C}$ nuclear magnetic resonance (NMR) techniques. All compounds elemental analysis results and mass analysis results are suitable with theoretical values.

FT-IR spectra of the complexes gave us important information about complexation. A comparison was made between ligands and their complex forms. Shifting frequency of $\mathrm{C}=\mathrm{N}$ double bond of ligands with complexation, ranging from $\sim 1,600$ to $\sim 1,700 \mathrm{~cm}^{-1}$ displays out the coordination of ligand to the metal. ${ }^{1} \mathrm{H}-\mathrm{NMR}$ gave us more important evidences about complexation than FT-IR. After complexation, $\mathrm{H}(4)$ proton shifts to downfield because $\mathrm{H}(4)$ proton is located near to the halogens. In the spectrums of L1 and AuL1, $\mathrm{R}=\mathrm{CH}_{3}$ peak was seen at $2.1 \mathrm{ppm}$. In AuL2's spectrum, the effect of strongly electronegative $\mathrm{CF}_{3}$ group was seen clearly. $\mathrm{H}(1)$ proton, which is patient from $\mathrm{CF}_{3}$ group, split up into two shifts from 7.89 to $7.72 \mathrm{ppm}$. This shifting implies that after coordination to metal center, electronegativity effect of $\mathrm{CF}_{3}$ decreases. In the spectrum of $\mathrm{L} 3$ and $\mathrm{AuL} 3, \mathrm{R}=\mathrm{H}$ peak is seen at $8.22 \mathrm{ppm}$ in the ligand and $9.12 \mathrm{ppm}$ in the complex. Shifting of proton to downfield displays the coordination of the ligand to the central metal atom.

\section{Catalytic effects of complexes on styrene polymerization}

In the first series of experiments, $\mathrm{L} 1 \mathrm{Au}-\mathrm{L} 3 \mathrm{Au}$ complexes were employed in catalytic amounts in bulk polymerization

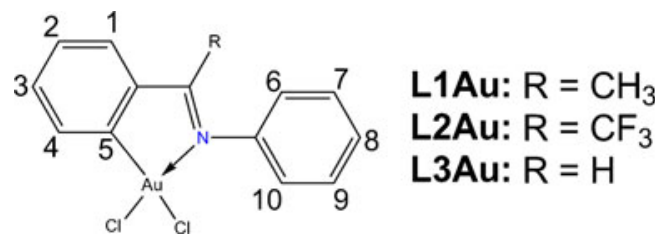

Fig. 1 Synthesized $\mathrm{Au}(\mathrm{III})$ complexes reactions involving styrene. Under these reaction conditions, no polymerization was observed. When 1 equiv of $\mathrm{NaBAr}_{4}^{\prime}$ was added to neat styrene solution as a halide scavenger, sudden polymerization was observed. To determine the effect of $\mathrm{NaBAr}_{4}{ }_{4}$, blank experiments were carried out. No reaction was observed when L1-L3 ligands were used as catalyst without metal center. Interestingly, $\mathrm{NaBAr}_{4}{ }_{4}$ alone with styrene gave polystyrene with high yield a-PS (Table 1; run nos., 1-5). When gold complexes added to the reaction media s-PS was formed (Fig. 2; Table 1; run nos., 6-20)

After these results were evaluated, series of experiments were conducted at room temperature with different solvents and results. Bulk polymerization was carried out at different catalyst concentrations but conversion did not pass $25 \%$ yield. Polymerization reactions were traced for $48 \mathrm{~h}$ and it was observed that polymerization reactions finalized at the end of 24th hour. Therefore we carried out several experiments in the presence of co-solvent. When toluene and chloroform was used as a co-solvent, conversion occurred in $24 \mathrm{~h}$. When toluene was used, PDI value of polymers were recorded under 2.0 but yields of polymerization reactions were pretty less (ranging from $2 \%$ to $5 \%$ within $5 \mathrm{~h}$; Table 1 , run nos., 10,15 , 20). Maximum yields of polymerization reactions were ranging from $35 \%$ to $50 \%$ after $24 \mathrm{~h}$. When chloroform was used as a co-solvent, conversion increased to $100 \%$, although the polydispersity was also higher than both bulk and toluene containing experiments. Conversion was inhibited completely after $24 \mathrm{~h}$ when THF or acetonitrile was added to the polymerization media. All complexes yielded syndiotactic polystyrene.

\section{Characterization of polymers}

The number and weight-average molecular weights $\left(M_{\mathrm{n}}\right.$ and $M_{\mathrm{w}}$ ) were determined by GPC in $\mathrm{CHCl}_{3}$ as calibrated with polystyrene standards. The triad tacticities of polymers were determined by ${ }^{13} \mathrm{C}$-NMR spectra in deuterated chloroform.

${ }^{1} \mathrm{H}-\mathrm{NMR}$ is very useful to identify polystyrene. Chemical shifts between 6.39 and $7.42 \mathrm{ppm}$ are aromatic hydrogen signals. The $1.72-2.43 \mathrm{ppm}$ are methyne hydrogen signals and chemical shifts between 0.97 and $1.76 \mathrm{ppm}$ are methylene hydrogen signals in polystyrene [21].

Figure 3 shows the comparison ${ }^{13} \mathrm{C}-\mathrm{NMR}$ spectrums of polystyrene in $\mathrm{CDCl}_{3}$ solution with catalyst and without catalyst. All spectrums were analyzed in terms of triads. Three main peaks left to right in Fig. 3 were assigned to isotactic triad $(\mathrm{mm})$, heterotactic triad $(\mathrm{mr})$, and syndiotactic triad (rr), respectively [22]. When we did not use a catalyst, the isotactic peak $(\mathrm{mm})$ seen as a major peak and the polymer obtained as isotactic reach atactic. On the other hand, when 
Table 1 Styrene polymerization datas ${ }^{\mathrm{a}}$ induced by $\mathrm{L} 1 \mathrm{Au}-\mathrm{L} 3 \mathrm{Au}$ and $\mathrm{NaBAr}_{4}^{\prime}$

${ }^{\text {a }}$ Equimolar mixtures of $\mathrm{L} 1 \mathrm{Au}-\mathrm{L} 3 \mathrm{Au}$ and $\mathrm{NaBAr}_{4}{ }_{4}(1 \times$ $\left.10^{-3} \mathrm{mmol}\right)$. [Styrene $] /[\mathrm{Au}]=2,500$ when $2 \mathrm{ml}$ of styrene employed

${ }^{\mathrm{b}}$ Isolated yield after precipitation with methanol

Determined by GPC using polystyrene standarts.

\begin{tabular}{llllllllll}
\hline Run no. & Catalyst & Styrene/ml & Co-solvent & $\mathrm{TON}^{\mathrm{b}}$ & $\mathrm{TOF}$ & $\mathrm{M}_{\mathrm{n}}{ }^{\mathrm{c}}$ & $\mathrm{M}_{\mathrm{w}}{ }^{\mathrm{c}}$ & $\mathrm{PDI}^{\mathrm{c}}$ & Tacticity \\
\hline 1 & - & 2 & None & 77 & 385 & 9184 & 20205 & 2.2 & a-PS \\
2 & - & 5 & None & 128 & 640 & 11254 & 30116 & 2.7 & a-PS \\
3 & - & 10 & None & 149 & 745 & 13194 & 31666 & 2.4 & a-PS \\
4 & - & 2 & PhMe & 92 & 460 & 6428 & 16713 & 2.6 & a-PS \\
5 & - & 2 & $\mathrm{CHCl}_{3}$ & 254 & 1270 & 10142 & 25355 & 2.5 & a-PS \\
6 & $\mathrm{~L} 1 \mathrm{Au}$ & 2 & None & 80 & 450 & 11216 & 26918 & 2.4 & s-PS \\
7 & $\mathrm{~L} 1 \mathrm{Au}$ & 5 & None & 100 & 500 & 14772 & 32388 & 2.2 & s-PS \\
8 & $\mathrm{~L} 1 \mathrm{Au}$ & 10 & None & 125 & 625 & 16391 & 29504 & 1.8 & s-PS \\
9 & $\mathrm{~L} 1 \mathrm{Au}$ & 2 & $\mathrm{PhMe}$ & 75 & 375 & 7732 & 14691 & 1.9 & s-PS \\
10 & $\mathrm{~L} 1 \mathrm{Au}$ & 2 & $\mathrm{CHCl}_{3}$ & 375 & 1875 & 12713 & 40682 & 3.2 & s-PS \\
11 & $\mathrm{~L} 2 \mathrm{Au}$ & 2 & None & 105 & 525 & 19388 & 40715 & 2.1 & s-PS \\
12 & $\mathrm{~L} 2 \mathrm{Au}$ & 5 & None & 118 & 590 & 21617 & 49719 & 2.3 & s-PS \\
13 & $\mathrm{~L} 2 \mathrm{Au}$ & 10 & None & 145 & 725 & 23916 & 55007 & 2.3 & s-PS \\
14 & $\mathrm{~L} 2 \mathrm{Au}$ & 2 & $\mathrm{PhMe}_{10}$ & 125 & 625 & 9721 & 19442 & 2.0 & s-PS \\
15 & $\mathrm{~L} 2 \mathrm{Au}$ & 2 & $\mathrm{CHCl}$ & 625 & 3125 & 17530 & 50837 & 2.9 & s-PS \\
16 & $\mathrm{~L} 3 \mathrm{Au}$ & 2 & None & 102 & 510 & 9152 & 20134 & 2.2 & s-PS \\
17 & $\mathrm{~L} 3 \mathrm{Au}$ & 5 & None & 109 & 545 & 10322 & 19612 & 1.9 & s-PS \\
18 & $\mathrm{~L} 3 \mathrm{Au}$ & 10 & None & 116 & 580 & 10932 & 24051 & 2.2 & s-PS \\
19 & $\mathrm{~L} 3 \mathrm{Au}$ & 2 & PhMe & 50 & 250 & 7122 & 12820 & 1.8 & s-PS \\
20 & $\mathrm{~L} 3 \mathrm{Au}$ & 2 & $\mathrm{CHCl}_{3}$ & 125 & 325 & 11367 & 32584 & 2.8 & s-PS \\
\hline & & & & & & & & &
\end{tabular}

we used Au catalyst, the stereoregularity of polymer changed and syndiotactic (rr) peak seen as a major peak.

Figure 4 shows the DSC thermogram of PS obtained by using L2Au as catalyst (Table 1, entry 13) and using without catalyst (Table 1, entry 3). Experiment without catalyst, the glass transition temperature $\left(T_{\mathrm{g}}=105^{\circ} \mathrm{C}\right)$ was obtained from the curve. No sharp melting peak above $200^{\circ} \mathrm{C}$ was observed. This indicates that the resulting polymer is amorphous. Also the melting points at 270 and $240^{\circ} \mathrm{C}$ were observed in the syndiotactic and isotactic polystyrene, respectively. No melting point was observed for polystyrene
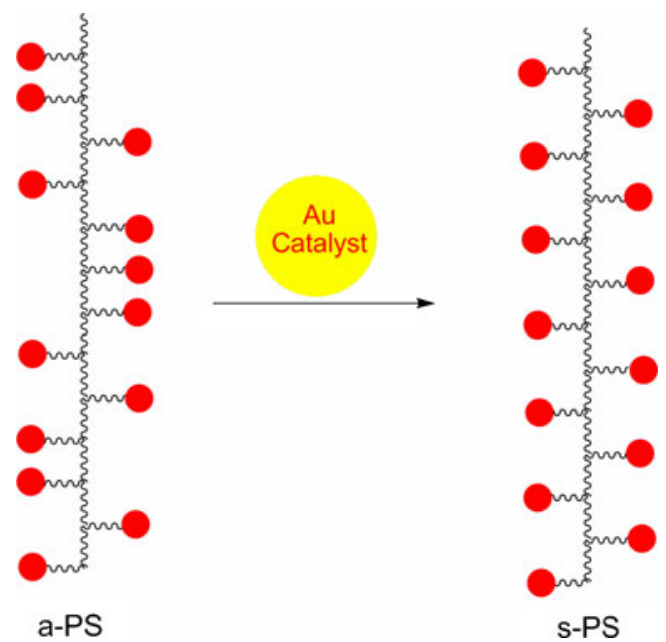

Fig. 2 Effect of $\mathrm{Au}(\mathrm{III})$ catalyst on styrene polymerization suggesting that the obtained polymer was atactic. Moreover, polystyrene obtained with using catalysts, a melting point at $266^{\circ} \mathrm{C}$ was observed which indicates that the synthesized polystyrene is in crystalline and syndiotactic form.

\section{Experimental}

\section{General}

All reactions were performed under dry, oxygen-free, nitrogen atmosphere. ${ }^{1} \mathrm{H}$ and ${ }^{13} \mathrm{C}$-NMR spectra were recorded at room temperature in $\mathrm{CDCl}_{3}$ on a Bruker/ BioSpin NMR $300 \mathrm{MHz}$ with $\mathrm{SiMe}_{4}(0.0 \mathrm{ppm})$ as internal reference. Elemental analysis was performed on a LECO CHNS-932. Melting points were measured on a Buchi Melting Point B-540 apparatus and they are uncorrected. FT-IR spectra were recorded on a Jasco $300 \mathrm{E}$ spectrometer with $\mathrm{KBr}$ palletes in the $4,000-400 \mathrm{~cm}^{-1}$ range. Atmospheric pressure chemical ionization mass spectra were recorded with an AGILENT 1100 MS LC-MS mass spectrometer. Molecular weights and molecular weight distributions were determined with a Knauer model gel permeation chromatograph (GPC) with $\mathrm{CHCl}_{3}$ as eluent and calibration was conducted with polystyrene standards. Differential scanning calorimetry (DSC) was obtained on Perkin Elmer Diamond DSC instrument under a nitrogen atmosphere with a heating/cooling rate of $20^{\circ} \mathrm{C} / \mathrm{min}$ of $\mathrm{NaBAr}_{4}^{\prime}$ was synthesized according to the reference [23]. 
Fig. 3 Comparative ${ }^{13} \mathrm{C}-\mathrm{NMR}$ spectrum of polystyrene

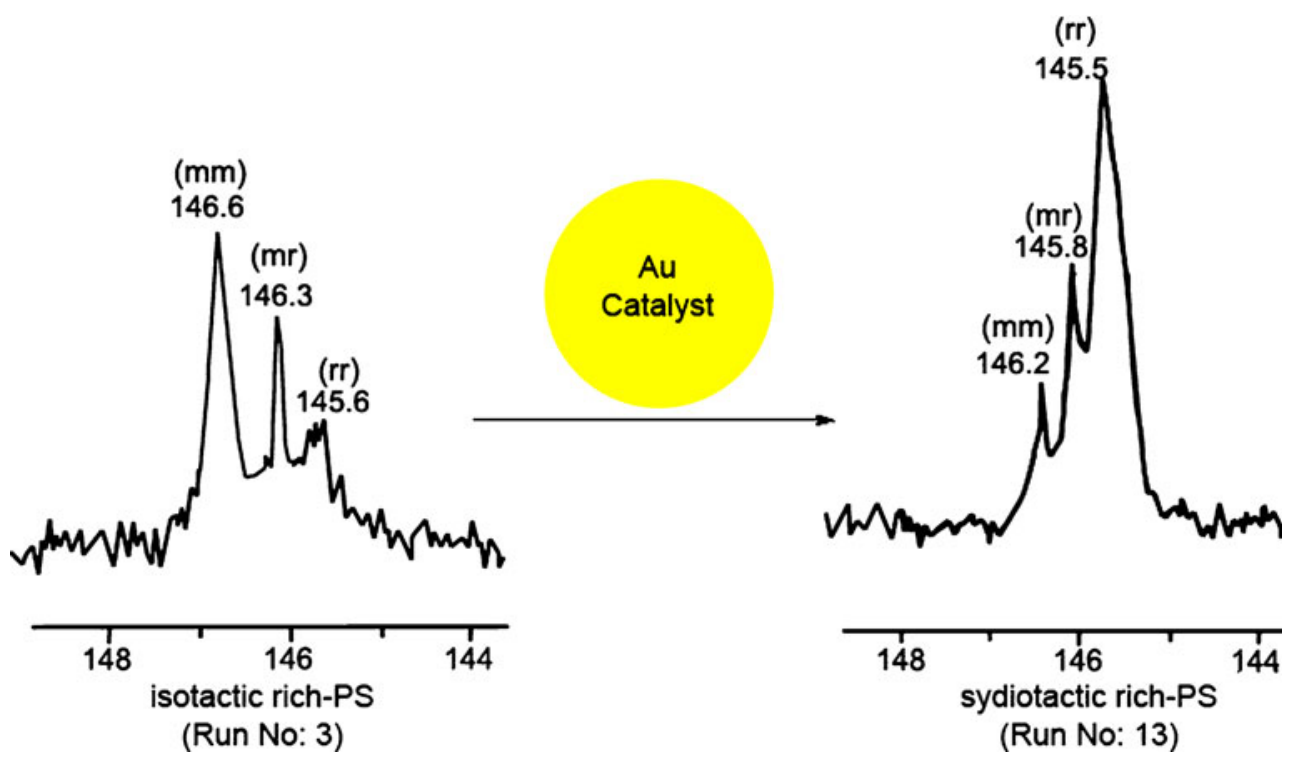

Preparation of ligands, general procedure

One millimole of acetylpyridine, pyridinecarboxyaldehyde, or acetophenone was dissolved in $2 \mathrm{ml}$ ethanol. Two millimoles aniline and $30 \mathrm{ml}$ of toluene were added dropwise to the above solution. In order to remove water from the solution, a DeanStark apparatus was used and resulting solution was refluxed for $2 \mathrm{~h}$. Precipitation was accomplished by cooling the mixture to room temperature. The precipitate (L1-L3) was isolated by filtration and then it was washed with cold methanol and finally it was dried under vacuum.

\section{(E)-N-(1-Phenylethylidene)benzenamine (L1)}

Yield 79\%. M.p. $122^{\circ} \mathrm{C}$. Anal. Calcd for $\mathrm{C}_{14} \mathrm{H}_{13} \mathrm{~N}$ : C, 86.43; H, 6.51; N, 7.06. Found, C, 86.12. H, 6.71. N, 7.17. ${ }^{1} \mathrm{H}-\mathrm{NMR}$ $\left(\mathrm{DMSO}_{-} \mathrm{d}_{6}\right): \delta 2.11(\mathrm{~s}, 3 \mathrm{H}), 6.90(\mathrm{~m}, 2 \mathrm{H}), 7.12(\mathrm{~m}, 2 \mathrm{H}), 7.25$ $(\mathrm{m}, 2 \mathrm{H}), 7.39(\mathrm{~m}, 2 \mathrm{H}), 7.48(\mathrm{~m}, 2 \mathrm{H}) \mathrm{ppm} .{ }^{13} \mathrm{C}-\mathrm{NMR}$ $\left(\mathrm{DMSO}_{-} \mathrm{d}_{6}\right): \delta 17.531,119.44,124.64,123.21,127.25$, $128.35,128.65,130.45,139.55,151.83,165.36$ ppm. FT-IR $\left(\mathrm{KBr}, v, \mathrm{~cm}^{-1}\right) 1630(\mathrm{C}=\mathrm{N})$. LC-MS $m / z 218\left(+\mathrm{Na}^{+}\right)$.

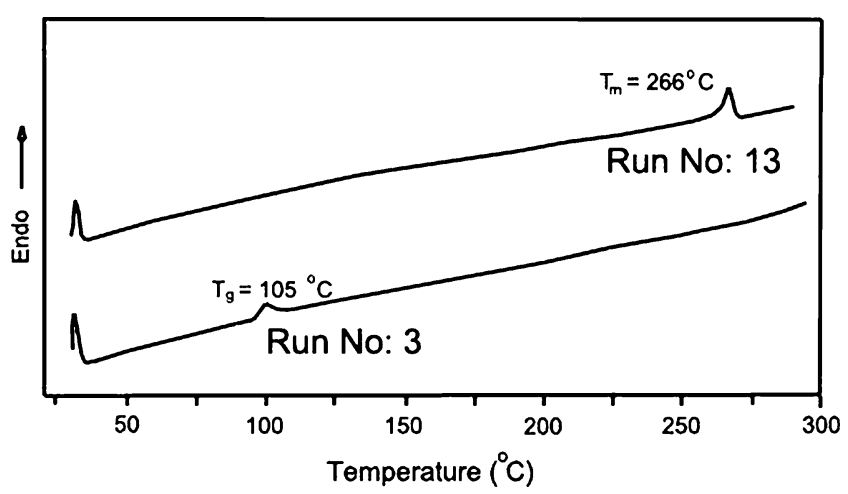

Fig. 4 Comparative DSC curve of polystyrene
(Z)-N-(2,2,2-Trifluoro-1-phenylethylidene)aniline (L2)

Yield $84 \%$. M.p. $138^{\circ}$ C. Anal. Calcd for $\mathrm{C}_{14} \mathrm{H}_{10} \mathrm{~F}_{3} \mathrm{~N}$ : C, 67.11; H, 4.41; N, 5.61. Found, C, 67.47. H, 4.04. N, 5.62. ${ }^{1}$ H-NMR $\left(\right.$ DMSO-d $\left._{6}\right): \delta 6.75(\mathrm{~m}, 2 \mathrm{H}), 6.86(\mathrm{~m}, 2 \mathrm{H}), 6.95$ $(\mathrm{m}, 1 \mathrm{H}), 7.24(\mathrm{~m}, 1 \mathrm{H}), 7.58(\mathrm{~m}, 2 \mathrm{H}), 7.89(\mathrm{~m}, 2 \mathrm{H}) \mathrm{ppm}$. ${ }^{13}$ C-NMR (DMSO-d 6 ): $\delta$ 120.25, 120.94, 125.18, 128.51, $129.88,130.53,131.25,132.04,151.51,158.04$ ppm. FTIR $\left(\mathrm{KBr}, v, \mathrm{~cm}^{-1}\right) 1598(\mathrm{C}=\mathrm{N})$. LC-MS m/z $272\left(+\mathrm{Na}^{+}\right)$.

\section{(E)-N-Benzylideneaniline (L3)}

Yield $79 \%$. M.p. $114^{\circ} \mathrm{C}$. Anal. Calcd for $\mathrm{C}_{13} \mathrm{H}_{12} \mathrm{~N}$ : C, 85.31; H, 6.88; N, 7.81. Found, C, 85.68. H, 6.64. N, 7.69. ${ }^{1} \mathrm{H}-\mathrm{NMR}$ $\left(\mathrm{DMSO}_{\mathrm{d}}\right): \delta 7.18(\mathrm{~m}, 6 \mathrm{H}), 7.37(\mathrm{~m}, 2 \mathrm{H}), 7.48(\mathrm{~m}, 2 \mathrm{H})$, $8.22(\mathrm{~s}, 1 \mathrm{H}) \mathrm{ppm} .{ }^{13} \mathrm{C}-\mathrm{NMR}$ (DMSO-d $)$ ): $\delta$ 126.62, 129.42, 129.51, 132.53, 137.18, 153.47, 161.11 ppm. FT-IR(KBr, v, $\left.\mathrm{cm}^{-1}\right) 1645(\mathrm{C}=\mathrm{N})$. LC-MS $m / z 204\left(+\mathrm{Na}^{+}\right)$.

\section{Preperation of complexes, general procedure}

A solution of the ligand (L1-L3; $1.00 \mathrm{mmol}$ ) in $\mathrm{CH}_{3} \mathrm{CN}$ $(5 \mathrm{ml})$ was added to a solution of $\mathrm{HAuCl}_{4}(1.00 \mathrm{mmol})$ in $\mathrm{H}_{2} \mathrm{O}(20 \mathrm{ml})$, forming a yellow suspension (Fig. 1). The suspension was stirred at room temperature for $2 \mathrm{~h}$ and a yellow solid was collected by filtration. After the precipitate was washed with $\mathrm{H}_{2} \mathrm{O}$ and a small amount of diethyl ether, it was suspended in mixed $\mathrm{CH}_{3} \mathrm{CN} / \mathrm{H}_{2} \mathrm{O}(50 \mathrm{ml} ; 1 / 5, v / v)$. The suspension was stirred at room temperature for $10 \mathrm{~min}$, and then it was heated at reflux for an hour. The reaction mixture was cooled to room temperature. After the filtration of this mixture, obtained precipitate was washed with $\mathrm{H}_{2} \mathrm{O}$. The precipitate was extracted with hot acetone or $\mathrm{CH}_{2} \mathrm{Cl}_{2}$, and the extract was filtered through filter paper. The solvent was removed by evaporation under vacuum and the 
residual solid (AuL1-AuL3) was soaked with a small amount of pre-cooled acetone and then hexanes.

[AuL1], $\left[\mathrm{AuCl}_{2}(\mathrm{~L} 1)\right]$, yield $58 \%$. M.p. $233^{\circ} \mathrm{C}$ (decomposition). Anal. Calcd for $\mathrm{C}_{14} \mathrm{H}_{12} \mathrm{AuCl}_{2} \mathrm{~N}$ : C, 36.39; $\mathrm{H}$, 2.62; N, 3.03. Found, C, 37.14. H, 2.33. N, 3.41. ${ }^{1} \mathrm{H}-\mathrm{NMR}$ $\left(\right.$ DMSO $\left.\mathrm{d}_{6}\right): \delta 2.11(\mathrm{~s}, 3 \mathrm{H}), 7.07(\mathrm{~m}, 2 \mathrm{H}), 7.33(\mathrm{~m}, 2 \mathrm{H})$, $7.49(\mathrm{~m}, 2 \mathrm{H}), 7.63(\mathrm{~m}, 2 \mathrm{H}), 7.91(\mathrm{~d}, 1 \mathrm{H}) \mathrm{ppm} .{ }^{13} \mathrm{C}-\mathrm{NMR}$ $\left(\right.$ DMSO-d $\left._{6}\right)$ : $\delta 18.51,121.24,124.64,128.31,129.89$, $129.30,130.93,135.63,141.16,152.09,166.42$ ppm. FT$\mathrm{IR}\left(\mathrm{KBr}, \mathrm{v}, \mathrm{cm}^{-1}\right) 1702(\mathrm{C}=\mathrm{N})$. LC-MS $m / z 484\left(+\mathrm{Na}^{+}\right)$.

[AuL2], $\left[\mathrm{AuCl}_{2}(\mathrm{~L} 2)\right]$, yield $69 \%$. M.p. $212-214^{\circ} \mathrm{C}$ (decomposition). Anal Calcd for $\mathrm{C}_{14} \mathrm{H}_{9} \mathrm{AuCl}_{2} \mathrm{~F}_{3} \mathrm{~N}$ : C, 32.58; $\mathrm{H}$, 1.76; N, 2.71. Found, C, 32.82. H, 1.54. N, 2.44. ${ }^{1} \mathrm{H}-\mathrm{NMR}$ $\left(\right.$ DMSO-d $\left._{6}\right): \delta 6,89(\mathrm{~m}, 1 \mathrm{H}), 6.97(\mathrm{~m}, 2 \mathrm{H}), 7.12(\mathrm{t}, 1 \mathrm{H}), 7.59$ (m, 1H), $7.83(\mathrm{~d}, 2 \mathrm{H}), 8.07(\mathrm{~d}, 2 \mathrm{H}) \mathrm{ppm} .{ }^{13} \mathrm{C}-\mathrm{NMR}$ (DMSO$\left.\mathrm{d}_{6}\right): \delta 160.31,153.74,134.26,133.22,132.92,131.25$, 130.97, 130.32, 126.27, 122.93, 122.14 ppm. FT-IR(KBr, v, $\left.\mathrm{cm}^{-1}\right) 1716(\mathrm{C}=\mathrm{N})$. LC-MS $m / z 514\left(+\mathrm{Na}^{+}\right)$.

[AuL3], [ $\mathrm{AuCl}_{2}$ (L3)], yield $77 \%$. M.p. $247^{\circ} \mathrm{C}$ (decomposition). Anal Calcd for $\mathrm{C}_{13} \mathrm{H}_{10} \mathrm{AuCl}_{2} \mathrm{~N}$ : C, 34.84; $\mathrm{H}$, 2.25; N, 3.13. Found, C, 35.02; H, 1.99; N, 3.38. ${ }^{1} \mathrm{H}-\mathrm{NMR}$ $\left(\right.$ DMSO-d $\left._{6}\right): \delta 9.12(\mathrm{~s}, 1 \mathrm{H}), 7.92(\mathrm{~d}, 1 \mathrm{H}), 7.76(\mathrm{~d}, 1 \mathrm{H}), 7,57$ $(\mathrm{m}, 4 \mathrm{H}), 7.38(\mathrm{~m}, 3 \mathrm{H})$ ppm. ${ }^{13} \mathrm{C}-\mathrm{NMR}\left(\mathrm{DMSO}_{\mathrm{d}}\right): \delta$ $163.72,154.21,138.10,135.61,133.70,131.21,130.88$, 130.11, $127.22 \mathrm{ppm}$. FT-IR(KBr, v, $\left.\mathrm{cm}^{-1}\right) 1708(\mathrm{C}=\mathrm{N})$. LC-MS $m / z 446\left(+\mathrm{Na}^{+}\right)$.

\section{Polymerization reactions}

In a $50 \mathrm{ml}$ ampoule, equipped with a magnetic stir bar, $1 \times$ $10^{-3} \mathrm{mmol}$ of $\mathrm{L} 1 \mathrm{Au}-\mathrm{L} 3 \mathrm{Au}$ were introduced along with 1 equivalent of $\mathrm{NaBAr}_{4}{ }_{4}$. The co-solvent and styrene were added via syringe and the mixture was stirred at room temperature. The initial brownish color mixture readily converted into a colorless mixture. At the end of the reaction, addition of $20 \mathrm{ml}$ of methanol into this colorless mixture induced the precipitation of the polymer. The polymer was separated by filtration and washed with two portions of $\mathrm{MeOH}$. Finally, the polymer was dried first under vacuum and later in the oven at $100^{\circ} \mathrm{C}$ for $12 \mathrm{~h}$ before isolated yield was calculated.

\section{Conclusions}

It's already known that, gold is very effective for both homogeneous and heterogeneous catalysis. But effects of gold on polymerization reactions are not explored. In conclusion, we have found that styrene can be polymerized in the presence of gold(III) complexes and $\mathrm{NaBAr}_{4}^{\prime}$. Collected results seem very interesting because gold catalysts did not affect the yield of reaction. But significantly they affect to the stereoregularity of the polymer. The problem is high polydispersity values and low yields of the resulting polymers. This problem can be achieved by using different ligand systems. Results are very promising to use gold catalysts in polymerization reactions.

Acknowledgments We gratefully acknowledge financial support for this work from TUBITAK, 108T240, Turkey.

Open Access This article is distributed under the terms of the Creative Commons Attribution License which permits any use, distribution, and reproduction in any medium, provided the original author(s) and source are credited.

\section{References}

1. Constable EC, Leese TA (1989) J Organomet Chem 363:419

2. Hashmi ASK (2003) Gold Bull 36:3-9

3. Hashmi ASK (2004) Gold Bull 37:51-65

4. Hashmi ASK, Hutchings GJ (2006) Angew Chem Int Ed 45:7896

5. Grohmann A, Riede J, Schmidbaur H (1992) Z Naturforsch B 47:1255-1260

6. M. A. Cinellu, A. Zucca, S. Stoccoro, G. Minghetti, M. Manassero, M. Sensoni, J. Chem. Soc. Dalton Trans, 1993, 4217

7. Soloshomok VA, Hayashi T (1994) Tetrahedron Asymetry 5(6):191

8. M. A. Cinellu, A. Zucca, S. Stoccoro, G. Minghetti, M. Manassero, M. Sansoni, J. Chem. Soc. Dalton Trans, 1995, 2865

9. H. Q. Liu, T. C. Chaung, S. M. Peng, C. M. Che, J. Chem. Soc. Chem. Commun, 1995, 1787

10. Parish RV (1998) Gold Bull 31(1):14

11. Vicente J, Chicote MT, Lozano MI, Huertas S (1999) Organometallics 18:753

12. Kronje S, Raubenheimer HG, Spies HSC, Esterhuysen C, Schmidbaur H, Schier A, Kruger GJ (2003) Dalton Trans 14:2859-2866

13. Hashmi ASK, Weyrauch JP, Rudolph M, Kurpejovic E (2004) Angew Chem Int Ed 43:5645-6547

14. Baundry-Barber D, Camus E, Dormund A, Visseaux M (1999) Appl Organomet Chem 13:813-817

15. Zang H, Chen Q, Qian Y, Huary J (2005) Appl Organomet Chem 19:68-75

16. Malang M, Newman TH (2002) Encyclopedia of Polymer Science and Technology. Wiley, New York, online version

17. Schellenberg J, Leder JJ (2006) T. Adv Polym Sci 25:141-151

18. Schellenberg J, Tomotsu N (2002) Prog Polym Sci 9:1925-1982

19. Schellenberg J (2009) Prog Polym Sci 8:688-718

20. J. Urbano, A. J. Hormigo, P. de Fremont, S. P. Nolan, M. M. DiazRequejo, P. J. Perez, Chem. Commun, 2008, 759

21. Li Y, Gao M, Wu Q (2008) Appl Organomet Chem 22:659

22. Istihara N, Seimiya T, Kuramoto M, Uoi M (1986) Macromolecules 19:2464

23. Brookhart M, Grant B, Volpe AF (1992) Organometallics 11:3920 